\title{
Neutronics analysis of the ITER Collective Thomson Scattering system
}

Lopes, A.; Luís, K. A.; Klinkby, E.; Nonbøl, E.; Jessen, M.; Moutinho, J.; Salewski, M.; Rasmussen, J.; Gonçalves, B.; Lauritzen, B.

Total number of authors:

13

Published in:

Fusion Engineering and Design

Link to article, DOI:

10.1016/j.fusengdes.2018.06.008

Publication date:

2018

Document Version

Peer reviewed version

Link back to DTU Orbit

Citation (APA):

Lopes, A., Luís, K. A., Klinkby, E., Nonbøl, E., Jessen, M., Moutinho, J., Salewski, M., Rasmussen, J.,

Gonçalves, B., Lauritzen, B., Korsholm, S. B., Larsen, H., \& Vidal, C. (2018). Neutronics analysis of the ITER Collective Thomson Scattering system. Fusion Engineering and Design, 134, 22-28.

https://doi.org/10.1016/j.fusengdes.2018.06.008

\section{General rights}

Copyright and moral rights for the publications made accessible in the public portal are retained by the authors and/or other copyright owners and it is a condition of accessing publications that users recognise and abide by the legal requirements associated with these rights.

- Users may download and print one copy of any publication from the public portal for the purpose of private study or research.

- You may not further distribute the material or use it for any profit-making activity or commercial gain

- You may freely distribute the URL identifying the publication in the public portal 


\title{
Neutronics analysis of the ITER Collective Thomson Scattering System
}

\author{
A. Lopes ${ }^{1}$, R. Luís ${ }^{1}$, E. Klinkby², E. Nonbøl' ${ }^{2}$, M. Jessen ${ }^{3}$, R. Moutinho ${ }^{1}$, M. Salewski ${ }^{3}$, J. Rasmussen $^{3}$, \\ B. Gonçalves ${ }^{1}$, B. Lauritzen ${ }^{2}$, S. B. Korsholm ${ }^{3}$, A. W. Larsen ${ }^{3}$, C. Vidal ${ }^{1}$ \\ ${ }^{1}$ Instituto de Plasmas e Fusão Nuclear, Instituto Superior Técnico, Universidade de Lisboa 1049-001 Lisboa, Portugal \\ ${ }^{2}$ DTU Nutech, Technical University of Denmark, DTU Risø Campus, Frederiksborgvej 399, DK-4000 Roskilde, Denmark \\ ${ }^{3}$ DTU Physics, Technical University of Denmark, Fysikvej, 2800 Kgs. Lyngby, Denmark
}

\begin{abstract}
The Collective Thomson Scattering (CTS) will be the ITER diagnostic responsible for measuring the alphaparticle velocity distribution. Using mirrors, a powerful microwave beam is directed into the plasma via an opening in the plasma-facing wall. The microwaves will scatter off fluctuations in the plasma, and the scattered signal is recorded after transmission through a series of mirrors and waveguides. Several components of the CTS system will be directly exposed to neutron radiation from the plasma which can change the properties of the components and reduce their lifetime. In this paper, a neutronics analysis is presented for the CTS system. A study on the influence of different materials on the nuclear heat loads in the launcher mirror is also presented, along with the design of a simple cooling system. All the studies were conducted using the Monte Carlo program MCNP6. The outputs, in particular the nuclear heat loads, will be used to perform the thermal analysis of the system.
\end{abstract}

Keywords: ITER, Collective Thomson Scattering, Neutronics, Flux, Nuclear Heat Loads, MCNP, CTS

\section{Introduction}

The Collective Thomson Scattering diagnostic (CTS) [1] will be implemented in ITER. It is based on characterizing $\mathrm{mm}$-waves scattered by the interaction between a 1MW injected source beam and ion-driven fluctuations in the plasma. The primary role of the diagnostic is to deliver spatially resolved information on the alpha-particle velocity distribution, with supplementary roles regarding measurements of the ion temperature and plasma rotation [2-4].

The front-end components of the ITER CTS diagnostic system are installed in the Drawer \#3 of the Equatorial Port Plug \#12 in the vacuum vessel partly exposed to the direct radiation plasma through apertures in the Diagnostic First Wall. They are thus subjected to nuclear loads from the plasma neutrons and from the gammas generated in nuclear interactions with the surrounding materials. The ionizing radiation will contribute to the thermal loads in the system and may cause irradiation-induced changes in the material properties, namely thermal and mechanical, which can compromise the integrity of the components during the lifetime of ITER.

The system, shown in Fig. 1, consists of a high-power and a lower-power transmission line with a solid wall in between. The high-power transmission line makes use of a powerful $1 \mathrm{MW} 60 \mathrm{GHz}$ gyrotron source, which through a system of waveguides and mirrors delivers the probing radiation from the closure plate of the equatorial port plug into the plasma via a cut-out in the diagnostic first wall [5].

In the low-power transmission line, the scattering signal is collected through a receiver cut-out in the diagnostic first wall and via mirrors and waveguides transmitted through the port cell and to the diagnostic building. Due to the large openings in the plasma facing first wall, the in-vessel port plug based CTS components will be subjected to significant loads by neutron and gamma radiation.

This paper presents the outcome of the nuclear analysis performed for the main components of the CTS system. The nuclear thermal loads obtained in this work will contribute to the loads specification of the CTS system and serve as input to the thermal analysis and stress analysis of the CTS in-vessel components. Such a thermal and stress analysis was presented for the originally proposed but later abandoned CTS receiver mirror on the high-field side [6].

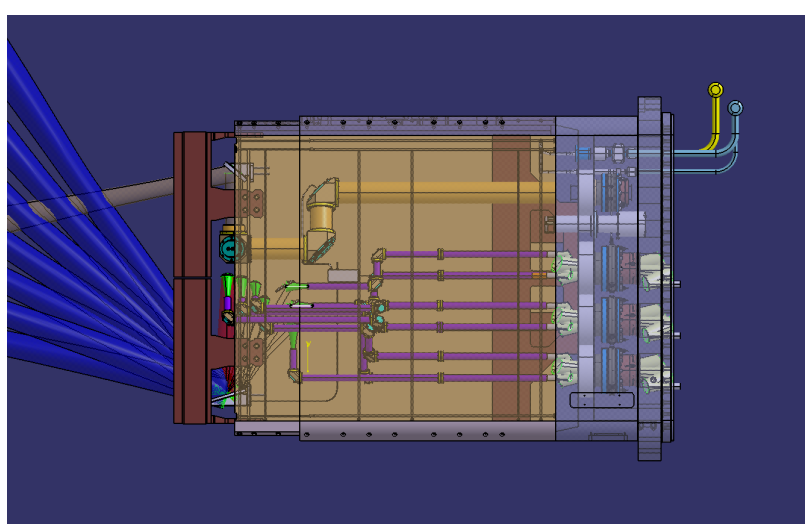

Fig. 1. CAD drawing of the ITER CTS diagnostics system.

\section{Neutronics Model}

In this paper we distinguish three types of neutronics models:

1. Reference model: standard ITER neutronics model, featuring a 20-degree portion of the most up-to-date global design information of the ITER machine; 
2. System-specific model: detailed input of the system which is the subject of the nuclear analysis (the CTS in-vessel components);

3. Integrated model: System-specific model integrated in the reference model.

The input for the neutronics model is a CAD Model in which some simplifications were made allowing simpler structured meshes. During the creation of the systemspecific model mainly spline surfaces, doubled surfaces and round edges were removed, which, in most cases, were replaced by sharp edges. The probe waveguide, in particular - which is seen at the top of Fig. 2 - was greatly simplified, due to the complexity of the original model, which featured several layers with a series of internal rings separating them. The inner radius of the waveguide was kept unchanged and the outer radius was adjusted to ensure volume conservation. In the remaining components - mitre bends, waveguide connectors, mirrors and waveguides - the simplifications consisted of removal of round edges. In the simplification process, the deviations between the volumes in the original model and the volumes in the simplified model were kept below $0.1 \%$, to make sure that the simplifications do not influence the results significantly.

In order to calculate the heat loads for the different mirrors and other components of the system, the neutronics CAD model was divided into separate cells, which are shown in Fig. 2 with different colours.

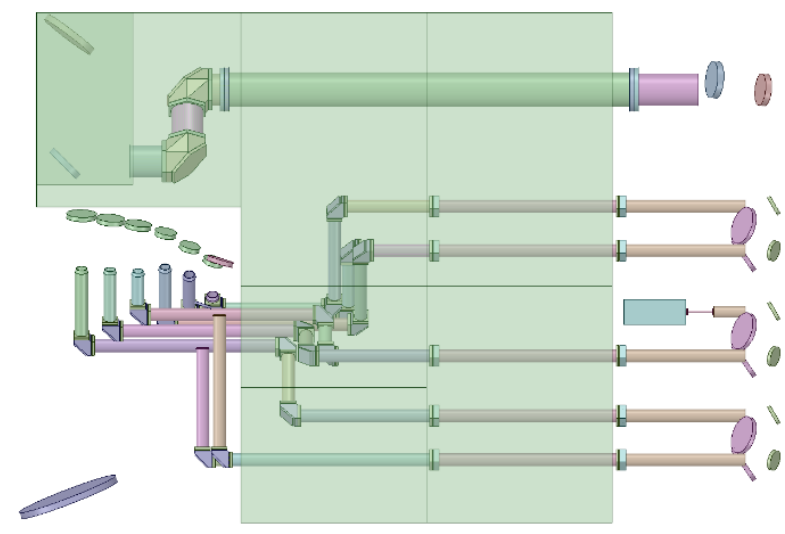

Fig. 2. Simplified neutronics CAD model of the CTS system. The green, transparent boxes represent cells to be filled with a $\mathrm{B}_{4} \mathrm{C}$ shielding mixture.

The neutronics simulations were performed using the Monte Carlo simulation program MCNP6, 1.0 [7]. The CAD model of the CTS system was simplified in order to avoid overlapping components in the most recent neutronics reference model of ITER - the C-model v2.1. The simplified CAD models were then converted to the STEP format, edited in ANSYS SpaceClaim [8] and imported into the CAD-based modelling program MCAM $[9,10]$ for a final conversion to the MCNP input format. This workflow is outlined in Fig. 3 .

Fig. 4 shows a vertical cross-section of the ITER reference MCNP model used in this work. The systemspecific MCNP model was created following the procedures illustrated in Fig. 3 and later integrated in this reference model. The system-specific model is shown in Fig. 5, which shows a sectional cut at $y=55 \mathrm{~cm}$ of the integrated MCNP model at the location of the CTS system.

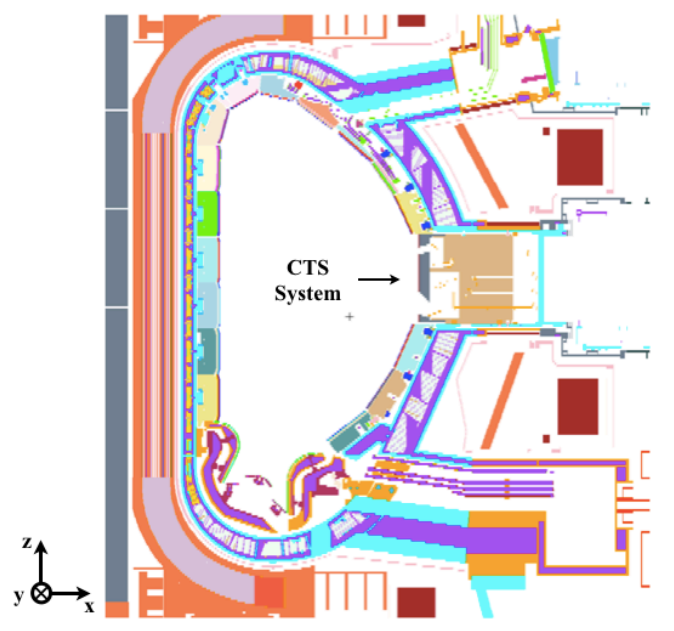

Fig. 4. Integrated MCNP model vertical cross-section, plane $\mathrm{y}=55 \mathrm{~cm}$

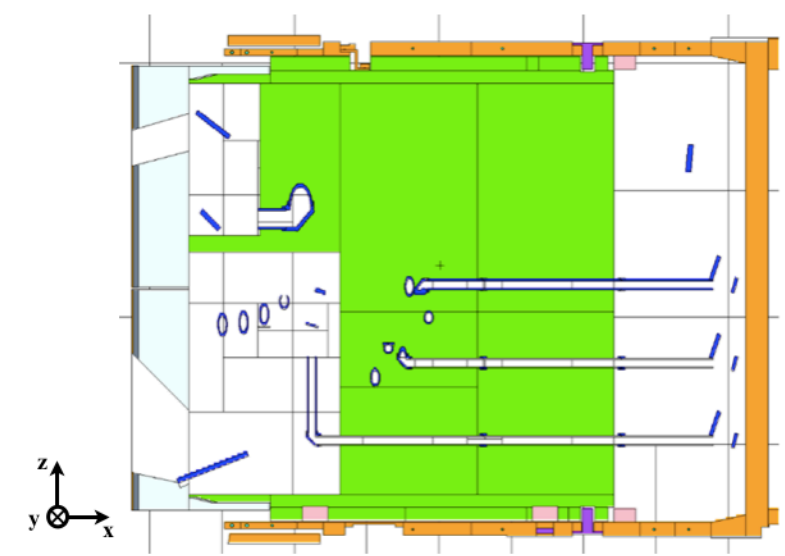

Fig. 5. System-specific MCNP model of the CTS system, plane $\mathrm{y}=55 \mathrm{~cm}$.

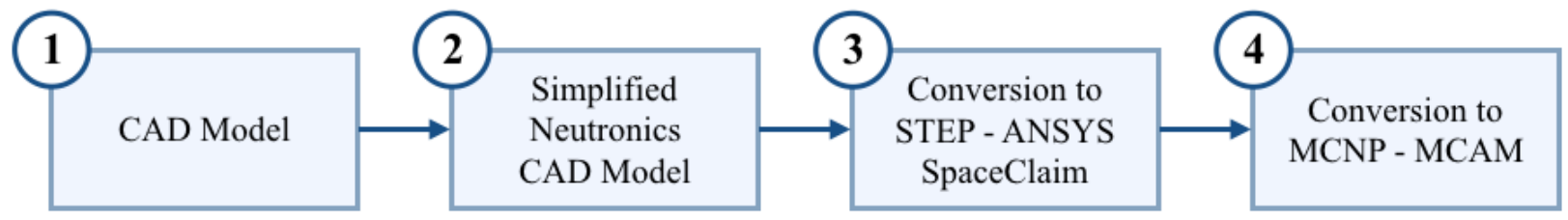

Fig. 3. Conversion steps from the CAD models in ENOVIA to the MCNP system-specific input. 
The integrated MCNP model was then used to perform the simulations. The parameters used for the simulations can be summarized as follows:

- $\quad$ The standard ITER D-T neutron source provided in the ITER reference model was used, normalized to $500 \mathrm{MW}$ of fusion power;

- The source is characterized by a Gaussian fusion energy spectrum with a mean value of $14.0791 \mathrm{MeV}$ and a FWHM of $0.889 \mathrm{MeV}$;

- The simulations include both neutron and gamma transport and the nuclear heat loads are reported separately. No other load combinations were considered;

- $\quad$ The ITER-grade steel 316L(N)-IG was the material used in the mirrors, waveguides and mitre bends of the CTS system, with a density of $7.93 \mathrm{~g} / \mathrm{cm}^{3}$. The material used in the shielding blocks, shown in Fig. 2 and 5, consists of a mix of Stainless Steel (31\%), boron carbide $\left(\mathrm{B}_{4} \mathrm{C}\right)$ with a density of $2.52 \mathrm{~g} / \mathrm{cm}^{3}$ $(41 \%)$, void $(27 \%)$, water $(1 \%)$ and other metals $(<1 \%)$ with an effective density of $3.26 \mathrm{~g} / \mathrm{cm}^{3}$;

- FENDL 2.1 cross section libraries [11] were used in the simulations of neutrons and MCPLIB84 libraries for the photons;

- $\quad$ F6 tallies were used to calculate the nuclear heat loads in the several cells of the system;

- F4 tallies were added to estimate the neutron and photon fluxes in the mirrors;

- Mesh tallies of the type 1 were implemented to obtain the neutron flux in the entire CTS system;

- $2 \times 10^{9}$ source particles were simulated, in order to obtain statistical uncertainty values below $10 \%$.

For the analysis and results presented in this paper, the mirrors will be numbered as shown in Fig. 6. Heat loads will also be presented for the cells of one of the collector lines shown in Fig. 7 and for the probe of the CTS system shown in Fig. 8.

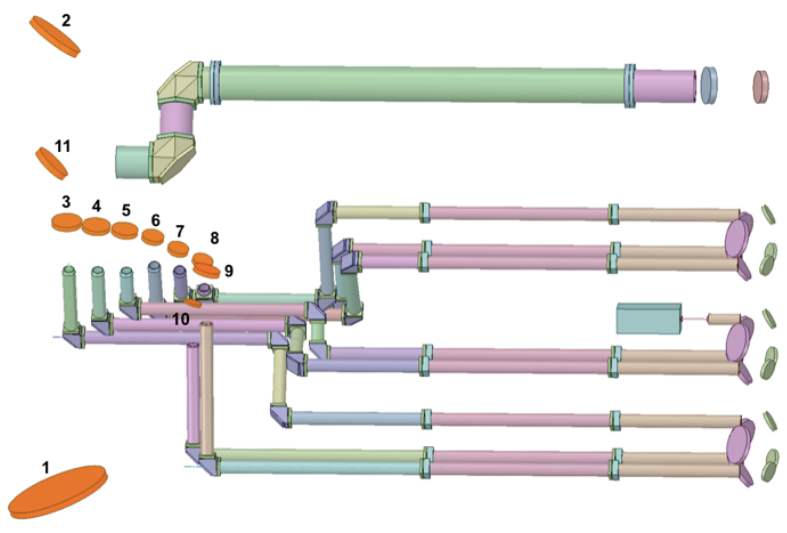

Fig. 6. Numbering scheme for the 11 mirrors of the CTS system.

\section{Results and Discussion}

The calculated heat loads in the several components of the CTS system are presented in Table 1, along with the relative contributions of neutrons and gammas to the energy deposition in each cell.

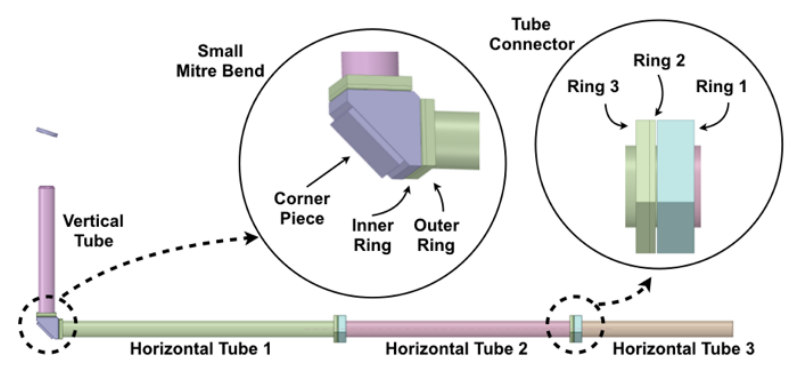

Fig. 7. Scheme of the collector line, including a small mitre bend and waveguide connectors.

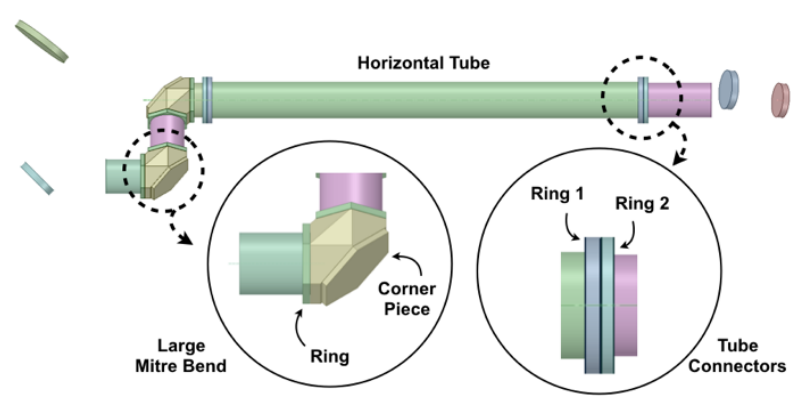

Fig. 8. Scheme of the probe system, including two large mitre bends and waveguide connectors.

As expected, the heat loads are higher in the launcher (mirror 2) and receiver (mirror 1, directly exposed to the plasma), reaching 1.54 and $3.01 \mathrm{~W} / \mathrm{cm}^{3}$, respectively. The difference is explained by the different locations and apertures. Due to its large size and mass, more energy is deposited in the receiver mirror $(\sim 5.2 \mathrm{~kW})$ than in the other ten mirrors combined. For the remaining mirrors, the heat loads vary between 0.4 and $0.7 \mathrm{~W} / \mathrm{cm}^{3}$. When it comes to the relative contributions from neutrons and photons, it is clear that photons are responsible for most of the energy deposition in all cells, which is also expected since all the components are made of stainless steel. Considering that the results presented in Table 1 do not take into account the diagnostics systems of the neighbouring drawers, they may be deemed as not conservative, as the introduction of gaps in the shielding and cut-outs in the first walls of the neighbouring systems can increase the heat loads in the components of the CTS system. For this reason, and in order to estimate conservative margins for the heat loads in the mirrors in particular, additional simulations were run with the shielding and the first walls removed from the neighbouring drawers. The results, presented in Table 2, show that under these conservative conditions, the heat loads in the launcher and receiver increase by $22 \%$ and $30 \%$, respectively, while in the remaining mirrors they increase by a factor between 2 and 3 .

In order to evaluate the effect on the nuclear heat loads of the introduction of a cooling system in the launcher mirror, water channels were added to the mirror, as shown in Fig. 9. Other options for structural materials of the launcher mirror were tested. Besides stainless steel, three different materials were tested in the launcher mirror: 
tungsten $\left(19.0 \mathrm{~g} / \mathrm{cm}^{3}\right), \mathrm{CuCrZr}\left(8.9 \mathrm{~g} / \mathrm{cm}^{3}\right)$ and an Inconel

alloy $\left(8.2 \mathrm{~g} / \mathrm{cm}^{3}\right)$.

Table 1. Nuclear heat loads in the CTS system.

\begin{tabular}{|c|c|c|c|c|c|c|}
\hline Components & Description & $\begin{array}{l}\text { Total Heat } \\
\text { Load Density } \\
\left(\mathrm{W} / \mathrm{cm}^{3}\right)\end{array}$ & $\begin{array}{l}\text { Total Heat } \\
\text { Load } \\
\text { (W) }\end{array}$ & $\begin{array}{c}\text { Statistical } \\
\text { Error } \\
(\%)\end{array}$ & $\begin{array}{l}\text { Heat Load } \\
\text { by } \\
\text { Neutrons } \\
(\%)\end{array}$ & $\begin{array}{c}\text { Heat Load } \\
\text { by Photons } \\
(\%)\end{array}$ \\
\hline \multirow{11}{*}{ Mirrors } & 1 (Receiver) & 3.009 & 5165.46 & 0.09 & 20.62 & 79.38 \\
\hline & 2 (Launcher) & 1.536 & 830.44 & 0.21 & 18.55 & 81.45 \\
\hline & 3 & 0.647 & 67.31 & 0.60 & 11.35 & 88.65 \\
\hline & 4 & 0.552 & 51.34 & 0.67 & 11.45 & 88.55 \\
\hline & 5 & 0.497 & 40.71 & 0.74 & 11.49 & 88.51 \\
\hline & 6 & 0.463 & 26.03 & 0.91 & 11.77 & 88.23 \\
\hline & 7 & 0.436 & 22.56 & 0.99 & 12.37 & 87.63 \\
\hline & 8 & 0.406 & 19.88 & 0.98 & 13.27 & 86.73 \\
\hline & 9 & 0.410 & 34.30 & 0.79 & 12.71 & 87.29 \\
\hline & 10 & 0.505 & 9.91 & 1.17 & 12.48 & 87.52 \\
\hline & 11 & 0.651 & 152.09 & 0.45 & 11.58 & 88.42 \\
\hline \multirow{3}{*}{$\begin{array}{l}\text { Small Mitre } \\
\text { Bend }\end{array}$} & Corner Piece & 0.878 & 61.34 & 0.61 & 19.09 & 80.91 \\
\hline & Outer Ring & 0.893 & 6.55 & 1.21 & 18.95 & 81.05 \\
\hline & Inner Ring & 0.911 & 2.15 & 1.73 & 18.50 & 81.50 \\
\hline \multirow{7}{*}{ Collector Line } & Vert. Tube & 0.807 & 157.55 & 0.32 & 16.84 & 83.16 \\
\hline & Horizontal Tube 1 & 0.226 & 96.16 & 0.49 & 15.81 & 84.19 \\
\hline & Horizontal Tube 2 & 0.001 & 0.43 & 7.60 & 20.30 & 79.70 \\
\hline & Horizontal Tube 3 & 0.000 & 0.03 & 26.42 & 28.59 & 71.41 \\
\hline & Connector Ring 1 & 0.005 & 0.09 & 11.62 & 11.82 & 88.18 \\
\hline & Connector Ring 2 & 0.004 & 0.01 & 15.22 & 14.10 & 85.90 \\
\hline & Connector Ring 3 & 0.005 & 0.03 & 14.16 & 15.03 & 84.97 \\
\hline \multirow{2}{*}{$\begin{array}{c}\text { Large Mitre } \\
\text { Bend } \\
\end{array}$} & Corner Piece & 0.102 & 61.54 & 0.78 & 12.70 & 87.30 \\
\hline & Ring & 0.061 & 2.09 & 2.20 & 12.83 & 87.17 \\
\hline \multirow{3}{*}{ Probe } & Horizontal Tube & 0.005 & 22.90 & 1.33 & 12.31 & 87.69 \\
\hline & Connector Ring 1 & 0.041 & 3.16 & 2.17 & 11.70 & 88.30 \\
\hline & Connector Ring 2 & 0.048 & 3.27 & 2.09 & 11.68 & 88.32 \\
\hline
\end{tabular}

Table 2. Estimation of conservative margins for the heat loads in the mirrors.

\begin{tabular}{|c|c|c|c|c|c|}
\hline Components & Description & $\begin{array}{c}\text { Total Heat Load } \\
\text { with Shielding } \\
- \text { HLO - } \\
\text { (W) }\end{array}$ & $\begin{array}{l}\text { Total Heat } \\
\text { Load without } \\
\text { Shielding } \\
\text { - HL1 - } \\
\text { (W) }\end{array}$ & $\begin{array}{l}\text { Total Heat Load } \\
\text { without shielding } \\
\text { and 1st Wall } \\
- \text { HL2 - } \\
\text { (W) }\end{array}$ & $\begin{array}{c}\text { Ratio } \\
\text { HL2/HL0 }\end{array}$ \\
\hline \multirow{11}{*}{ Mirrors } & 1 1 (Receiver) & 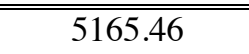 & 5178.51 & 6295.58 & 1.22 \\
\hline & 2 (Launcher) & 830.44 & 832.76 & 1079.35 & 1.30 \\
\hline & 3 & 67.31 & 68.86 & 200.86 & 2.98 \\
\hline & 4 & 51.34 & 53.21 & 154.84 & 3.02 \\
\hline & 5 & 40.71 & 42.69 & 116.77 & 2.87 \\
\hline & 6 & 26.03 & 27.41 & 72.13 & 2.77 \\
\hline & 7 & 22.56 & 24.13 & 62.13 & 2.75 \\
\hline & 8 & 19.88 & 21.04 & 54.46 & 2.74 \\
\hline & 9 & 34.30 & 37.59 & 98.57 & 2.87 \\
\hline & 10 & 9.91 & 10.45 & 26.24 & 2.65 \\
\hline & 11 & 152.09 & 153.20 & 273.31 & 1.80 \\
\hline
\end{tabular}




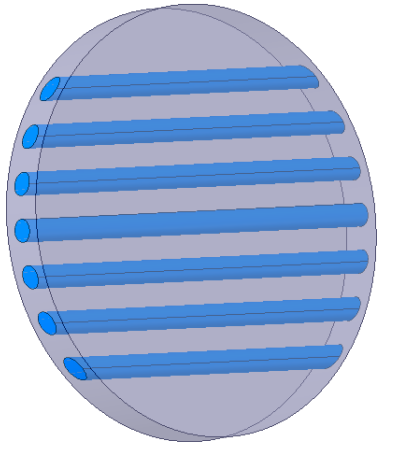

Fig. 9. Launcher mirror with a conceptual design of a water cooling system.

The results, presented in Table 3, show that the heat loads in the mirror material are barely affected by the introduction of water in all the materials except tungsten, where an increase of $11 \%$ is observed. This is because water moderates neutrons more effectively than the mirror material (especially when that material is tungsten), and the radiative capture cross section is higher for lowerenergy neutrons. The increase in the production of gammas is therefore more pronounced in tungsten which contributes with more than $98 \%$ to the total heat load.

The neutron and photon spectra were determined for the mirrors of the system, using the vitamin-J bin structure. Fig. 10 and Fig. 11 show the neutron and photon fluxes for the mirrors with the highest fluxes, namely mirror 1 (receiver), mirror 2 (launcher) and mirror 11, which are closest to the plasma. The spectra for the remaining mirrors are shown in Fig. 12 and Fig. 13.

As expected, there is a peak at $14 \mathrm{MeV}$ for neutrons. In the cells directly exposed to the plasma, this peak rises above the rest of the spectrum, while in the cells located behind the blanket module there are in most cases higher fluxes of scattered lower energy neutrons. The photon fluxes are in general highest for energies between 100 $\mathrm{keV}$ and $10 \mathrm{MeV}$. The total neutron flux in the receiver is
$2.25 \times 10^{14}$ neutrons $/ \mathrm{cm}^{2} / \mathrm{s}$, while the total photon flux is $1.16 \times 10^{14}$ photons $/ \mathrm{cm}^{2} / \mathrm{s}$.

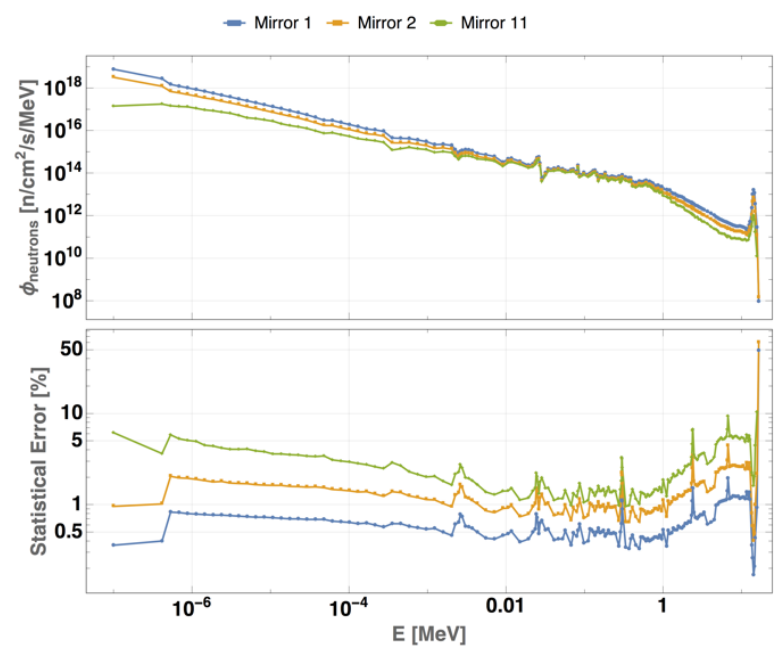

Fig. 10. Neutron fluxes $\left(\mathrm{n} / \mathrm{cm}^{2} / \mathrm{s} / \mathrm{MeV}\right)$ and statistical errors in mirrors 1 (receiver), 2 (launcher) and 11.

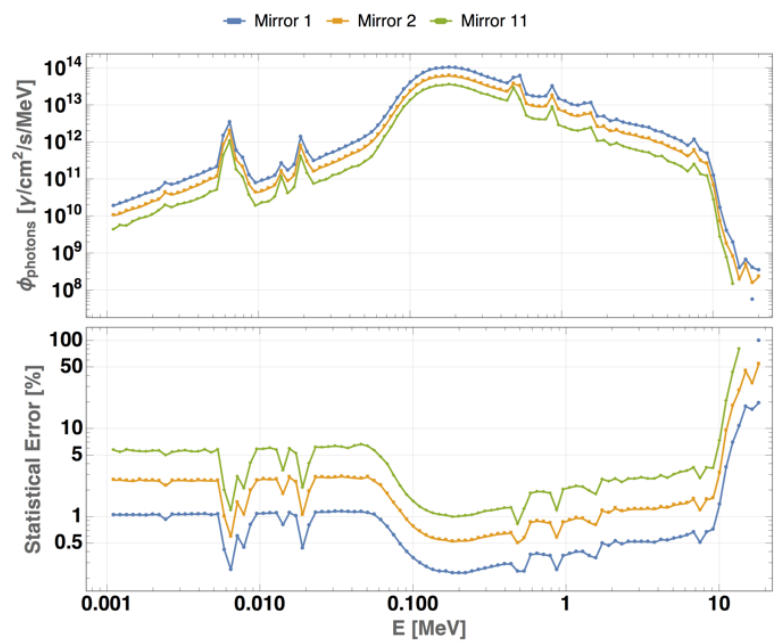

Fig. 11. Photon fluxes $\left(\gamma / \mathrm{cm}^{2} / \mathrm{s} / \mathrm{MeV}\right)$ and statistical errors in mirrors 1 (receiver), 2 (launcher) and 11.

Table 3. Heat Loads in the launcher, with and without cooling system.

\begin{tabular}{|c|c|c|c|c|c|c|c|}
\hline Material & Component & $\begin{array}{c}\text { Total } \\
\text { Heat } \\
\text { Load } \\
\text { Density } \\
\left(\mathrm{W} / \mathrm{cm}^{3}\right)\end{array}$ & $\begin{array}{l}\text { Stat. } \\
\text { Error } \\
(\%)\end{array}$ & $\begin{array}{l}\text { Heat Load } \\
\text { Density by } \\
\text { Neutrons } \\
\left(\mathrm{W} / \mathrm{cm}^{3}\right)\end{array}$ & $\begin{array}{l}\text { Stat. } \\
\text { Error } \\
(\%)\end{array}$ & $\begin{array}{c}\text { Heat } \\
\text { Load } \\
\text { Density } \\
\text { by } \\
\text { Neutrons } \\
(\%)\end{array}$ & $\begin{array}{c}\text { Heat } \\
\text { Load } \\
\text { Density } \\
\text { by } \\
\text { Photons } \\
(\%)\end{array}$ \\
\hline \multirow{3}{*}{$\begin{array}{l}\text { Stainless } \\
\text { Steel }\end{array}$} & Mirror (without cooling system) & 1.53 & 0.21 & 0.28 & 0.21 & 18.55 & 81.45 \\
\hline & Mirror (with cooling system) & 1.58 & 0.94 & 0.28 & 0.94 & 17.84 & 82.16 \\
\hline & Water Tubes & 1.46 & 2.21 & 1.32 & 2.39 & 89.99 & 10.01 \\
\hline \multirow{3}{*}{ Tungsten } & Mirror (without cooling system) & 3.26 & 0.90 & 0.05 & 0.81 & 1.67 & 98.33 \\
\hline & Mirror (with cooling system) & 3.63 & 0.90 & 0.05 & 0.82 & 1.48 & 98.52 \\
\hline & Water Tubes & 1.43 & 2.29 & 1.32 & 2.44 & 91.79 & 8.21 \\
\hline \multirow{3}{*}{$\mathrm{CuCrZr}$} & Mirror (without cooling system) & 1.63 & 0.91 & 0.26 & 0.92 & 15.85 & 84.15 \\
\hline & Mirror (with cooling system) & 1.67 & 0.93 & 0.26 & 0.94 & 15.44 & 84.56 \\
\hline & Water Tubes & 1.46 & 2.22 & 1.32 & 2.40 & 90.37 & 9.63 \\
\hline \multirow{3}{*}{ Inconel } & Mirror (without cooling system) & 1.63 & 0.20 & 0.46 & 0.21 & 27.99 & 72.01 \\
\hline & Mirror (with cooling system) & 1.67 & 0.20 & 0.46 & 0.21 & 27.60 & 72.40 \\
\hline & Water Tubes & 1.47 & 0.50 & 1.32 & 0.83 & 90.31 & 9.69 \\
\hline
\end{tabular}




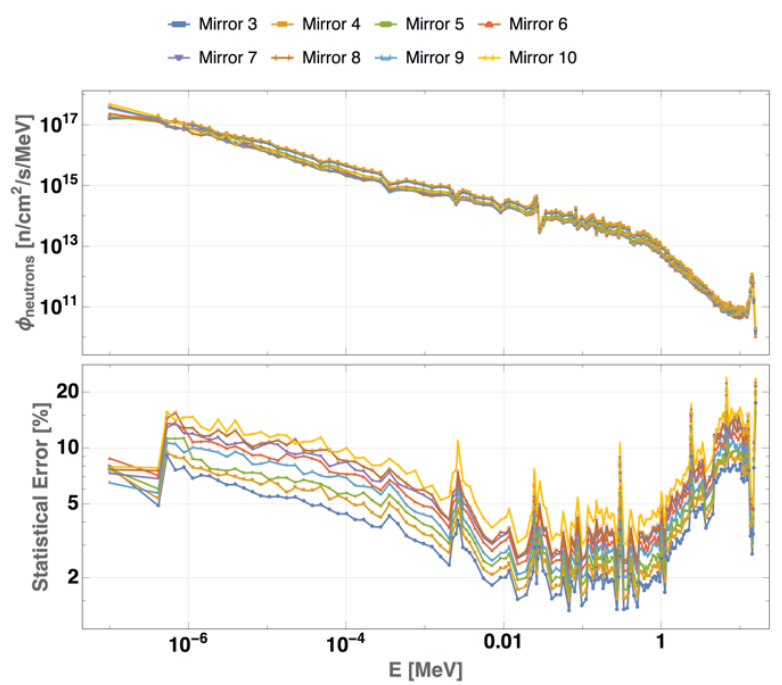

Fig. 12. Neutron fluxes $\left(\mathrm{n} / \mathrm{cm}^{2} / \mathrm{s} / \mathrm{MeV}\right)$ and statistical errors in mirrors 3 to 10 .

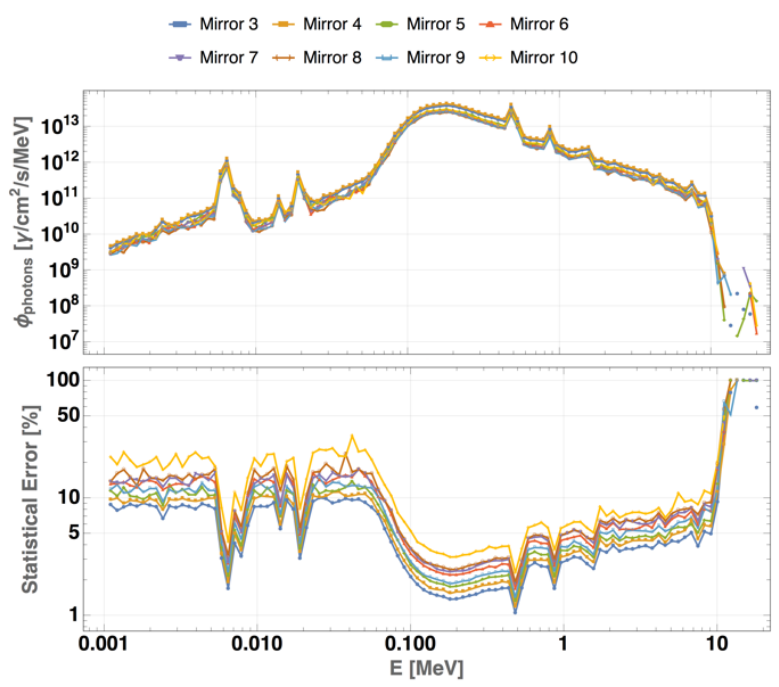

Fig. 13. Photon fluxes $\left(\gamma / \mathrm{cm}^{2} / \mathrm{s} / \mathrm{MeV}\right)$ and statistical errors in mirrors 3 to 10 .

Even when $2 \times 10^{9}$ source particles are simulated, the statistics at the back-end of the system are lower than desirable. As shown in Table 1, this is seen in particular for some components of the collector line where errors rise above $10 \%$ due to lack of statistics. For this reason, the ADVANTG software package [12] was used to generate the weight windows shown in Fig. 15, in order to increase the efficiency of the simulations. The fwcadis method was employed, and the closure plate was chosen as the tally cell towards which the simulation is biased.

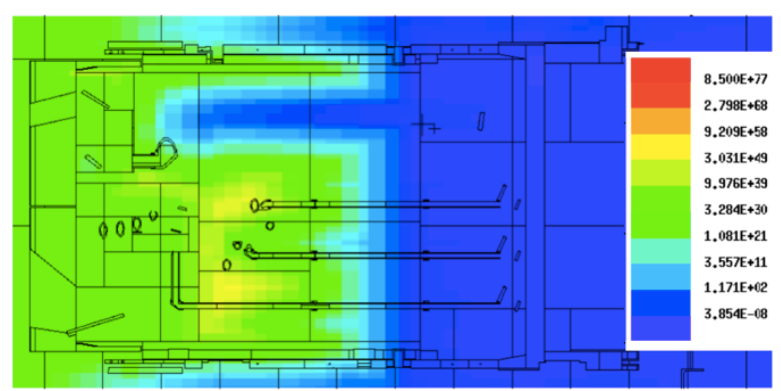

Fig. 15. Weight windows generated using the ADVANTAG package, plane $\mathrm{y}=50 \mathrm{~cm}$.
The mesh tallies calculated using these weight windows are presented for the plane $y=55 \mathrm{~cm}$ in Figs. 16 to 18 , for three energy bins (0-0.1 MeV, $0.1-1 \mathrm{MeV}$ and 1-20 MeV, respectively).

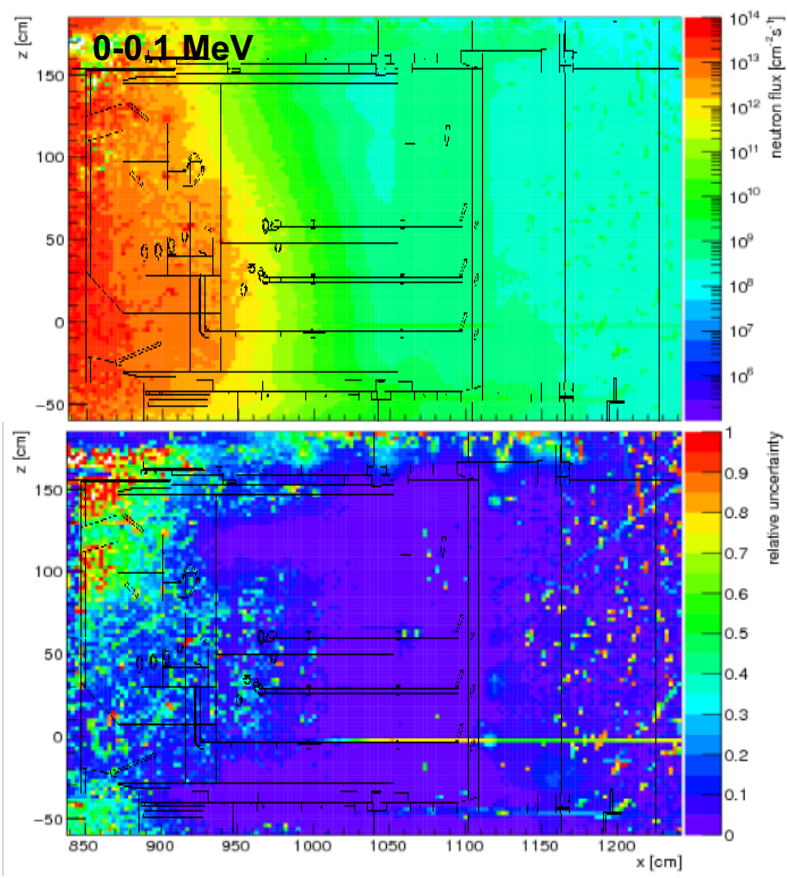

Fig. 16. Neutron fluxes $\left(\mathrm{n} / \mathrm{cm}^{2} / \mathrm{s}\right)$ and statistical errors in the CTS system, plane $y=55 \mathrm{~cm}$, for neutron energies between 0 and $0.1 \mathrm{MeV}$.

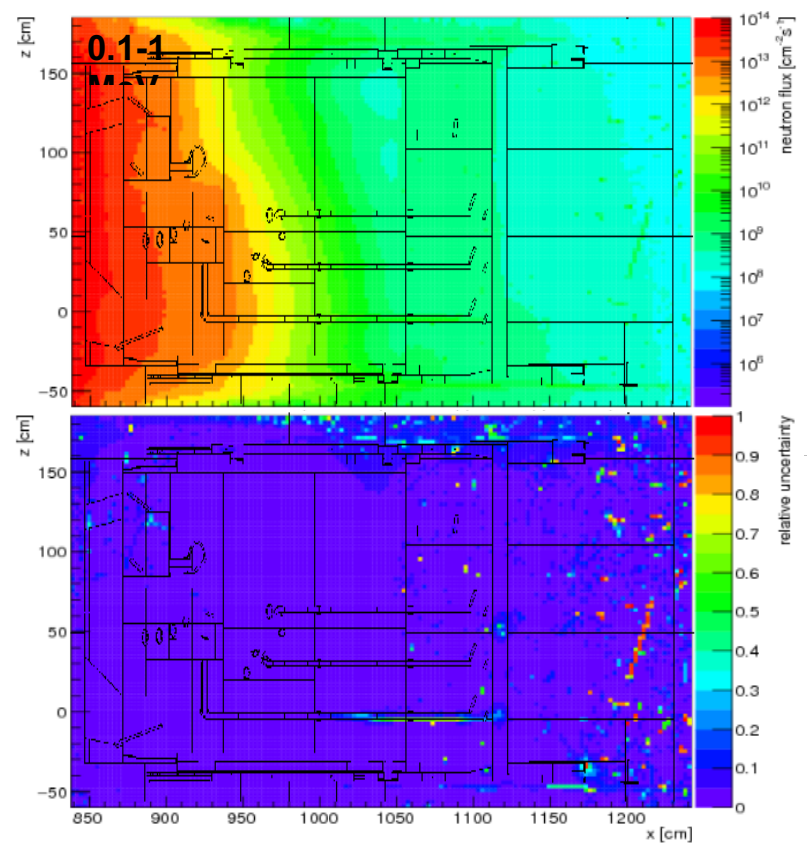

Fig. 17. Neutron fluxes $\left(\mathrm{n} / \mathrm{cm}^{2} / \mathrm{s}\right)$ and statistical errors in the CTS system, plane $y=55 \mathrm{~cm}$, for neutron energies between 0.1 and $1 \mathrm{MeV}$.

The fluxes at the closure plate are of the order of $10^{8}$ neutrons $/ \mathrm{cm}^{2} / \mathrm{s}$ for energies between 0 and $1 \mathrm{MeV}$, being approximately one order of magnitude lower in the 1-20 $\mathrm{MeV}$ energy range. The errors are, in general, low for the three energy ranges, with the exception of the errors seen in Fig. 16 for some of the plasma facing components, which can be explained by the low fluxes of low-energy 
neutrons in that area. The neutron streaming in some of the CTS waveguides, visible in the mesh tally plots, contributes to the neutron fluxes at the closure plate.

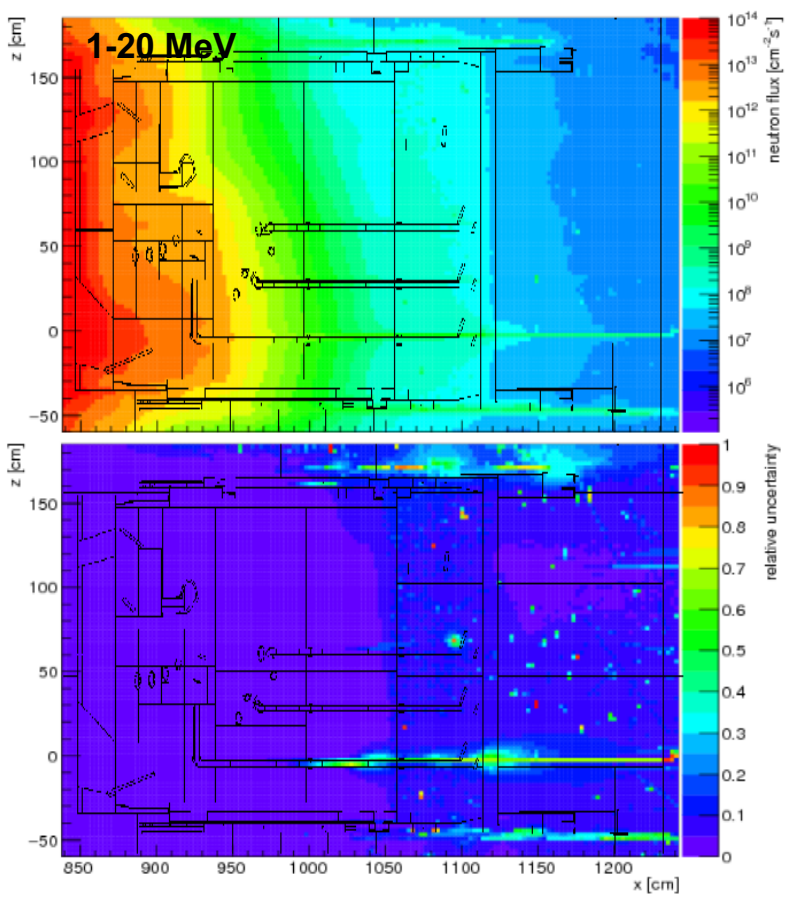

Fig. 18. Neutron fluxes $\left(\mathrm{n} / \mathrm{cm}^{2} / \mathrm{s}\right)$ and statistical errors in the CTS system, plane $\mathrm{y}=55 \mathrm{~cm}$, for neutron energies between 1 and $20 \mathrm{MeV}$.

\section{Conclusions}

The magnitudes of the nuclear heat loads and neutron fluxes obtained in the simulations are consistent with results from previous analyses. Peak values of the order of $3 \mathrm{~W} / \mathrm{cm}^{3}$ were obtained in the plasma-facing receiver mirror, where a total power of $5.2 \mathrm{~kW}$ is deposited; in the launcher, the heat load is $1.5 \mathrm{~W} / \mathrm{cm}^{3}$. The heat loads in the remaining components are always below $1 \mathrm{~W} / \mathrm{cm}^{3}$ : in the remaining nine mirrors they are all between 0.4 and 0.7 $\mathrm{W} / \mathrm{cm}^{3}$. For components located at the back of the port plug, the heat loads are below $10 \mathrm{~mW} / \mathrm{cm}^{3}$.

To estimate conservative margins for the heat loads in the mirrors, new simulations were run with the shielding and the first walls removed from the neighbouring drawers. The results show that under these conservative conditions the heat loads in the launcher and receiver increase by $22 \%$ and $30 \%$, respectively, while in the remaining mirrors they increase by up to a factor of 3 . These margins could be considered in the thermal analyses of the CTS system.

Based on the results of the nuclear analysis, future designs of the CTS system will aim at reducing the neutron fluxes at the closure plate as much as possible, in order to minimize the contribution from the CTS system to the shutdown dose rates in the port interspace.

\section{Acknowledgments}

The work leading to this publication has been funded partially under the framework of the Specific Grant 04 (SG04) of the Fusion for Energy (F4E) Framework Partnership Agreement 393 (F4E-FPA-393) which consists in executing the R\&D of the components of the diagnostic to be installed in the equatorial port plug \#12 drawer number 3. IST activities also received financial support from Fundação para a Ciência e Tecnologia (FCT) through the individual grant PD/BD/114322/2016 under the APPLAuSE Doctoral Program. This publication reflects the views only of the author, and Fusion for Energy cannot be held responsible for any use, which may be made of the information contained therein.

\section{References}

[1] S.B. Korsholm et al, "Collective Thomson scattering capabilities to diagnose fusion plasmas," Nucl. Instr. Meth. Phys. Res. A, vol. 623, pp. 677- 680, (2010)

[2] S.B. Korsholm et al, "Measurements of Intrinsic Ion Bernstein Waves in a Tokamak by Collective Thomson Scattering," Phys. Rev. Lett., vol. 106, 165004, (2011)

[3] M. Stejner et al, "The prospect for fuel ion ratio measurements in ITER by collective Thomson scattering," Nucl. Fusion, vol. 52, 023011, (2012)

[4] M. Salewski et al, "Comparison of collective Thomson scattering signals due to fast ions in ITER scenarios with fusion and auxiliary heating," Plasma Phys. Control. Fusion, vol. 51, 035006, (2009)

[5] S.B. Korsholm et al, "High Power Microwave Diagnostic for the Fusion Energy Experiment ITER”, IEEE $20161^{\text {st }}$ International Conference on Infrared, Milimeter, and Terahertz waves, Sep 25-30 (2016)

[6] M. Salewski et al, "Investigations of the first mirror heating for the collective Thomson scattering diagnostic in ITER”, Rev. of Sci. Instr. 79, 10E729 (2008)

[7] J.T. Goorley, et al., "Initial MCNP6 Release Overview MCNP6 version 1.0" (2013)

[8] ANSYS@ Academic Associate, Release 17.0

[9] Y. Li et al. Benchmarking of MCAM 4.0 with the ITER 3D model, Fusion Engineering and Design 82 (2007) 28612866

[10] Y. Wu, FDS Team, CAD-based interface programs for fusion neutron transport simulation, Fusion Engineering and Design 84 (2009) 1987-1992

[11] D. Lopez Aldama and A. Trkov, FENDL-2.1 - Update of an Evaluated Nuclear Data Library for Fusion Applications, INDC(NDS)-467, (2004)

[12] S.W. Mosher et al, ADVANTG - An Automated Variance Reduction Parameter Generator, ORNL/TM 2013/416 Rev. 1, Oak Ridge National Laboratory (2015) 